\title{
Associations of self-reported and objectively measured sleep disturbances with depression among primary caregivers of children with disabilities
}

\author{
This article was published in the following Dove Press journal: \\ Nature and Science of Sleep \\ 10 June 2016 \\ Number of times this article has been viewed
}

\section{Olivia R Orta' \\ Clarita Barbosa' \\ Juan Carlos Velez ${ }^{2}$ \\ Bizu Gelaye' \\ Xiaoli Chen' \\ Lee Stoner ${ }^{3}$ \\ Michelle A Williams' \\ 'Harvard T.H. Chan School of Public Health, Harvard University, Boston, MA, USA; 'Worker's Hospital, The \\ Chilean Safety Association, Santiago, Chile; ${ }^{3}$ School of Sport and Exercise, Massey University, Wellington, New Zealand}

Correspondence: Olivia R Orta Epidemiology Department, Harvard T.H. Chan School of Public Health, 677 Huntington Avenue, Boston, MA 02115

Email Orta@mail.harvard.edu
Objective: The objective of this study was to determine the association between sleep and depression using both self-reported (subjective) and actigraphic (objective) sleep traits.

Methods: A cross-sectional study was conducted among 175 female primary caregivers of children with disabilities receiving care at a rehabilitation center in Punta Arenas, Chile. The eight-item Patient Health Questionnaire was used to ascertain participants' depression status. The Pittsburgh Sleep Quality Index was used to define subjective, or perceived, sleep quality. Wrist-worn actigraph monitors, worn for seven consecutive nights, were used to characterize objective sleep quality and disturbances. Interviewer-administered questionnaires were used to collect information on sociodemographic and lifestyle factors. Linear regression models were fit using continuous sleep parameters as the dependent variables and depression status as the independent variable. Multivariable models were adjusted for body mass index, marital status, smoking status, education level, and children's disabilities.

Results: Using an eight-item Patient Health Questionnaire score $\geq 10,26.3 \%$ of participants presented with depression. Depressed women were more likely to self-report overall poorer (subjective) sleep compared to non-depressed women; however, differences in sleep were not consistently noted using actigraphic (objective) sleep traits. Among the depressed, both sleep duration and total time in bed were significantly underestimated. In multivariable models, depression was negatively associated with sleep duration using both subjective $(\beta=-0.71$, standard error $[\mathrm{SE}]=0.25 ; P=0.006)$ and objective sleep $(\beta=-0.42, \mathrm{SE}=0.19 ; P=0.026)$.

Conclusion: The association between sleep and depression differed comparing subjective and objective methods of assessment. Research strategies allowing for the integration of both perceived and objective measures of sleep traits are encouraged.

Keywords: actigraphy, caregiver, Chile, depression, Pittsburgh Sleep Quality Index, sleep

\section{Introduction}

Poor sleep is ubiquitous, compromising alertness and psychological health. The international prevalence of poor sleep is estimated to range from $17 \%$ to $26 \%{ }^{1-3}$ and is associated with depression using different study designs and populations. ${ }^{1,3-7}$ However, the method of sleep assessment varies among depression studies. Subjective sleep parameters rely on retrospective self-reports using questionnaires and surveys. One example of a subjective sleep instrument is the Pittsburgh Sleep Quality Index (PSQI). ${ }^{8}$ Rather than self-reports, objective sleep parameters rely on monitoring of sleep-wake activity using electronic instrumentation. One example of an objective 
sleep instrument is wrist actigraphy, which estimates sleepwake activity based on motor activity. ${ }^{9}$ A number of studies have shown that results from subjective and objective sleep measures differ. These studies have included healthy men and women, ${ }^{10,11}$ the depressed, ${ }^{12-14}$ pregnant women, ${ }^{15,16}$ women with severe premenstrual syndrome, ${ }^{17}$ the elderly, ${ }^{18}$ and caregivers. ${ }^{19}$ Understanding the differences between subjective and objective sleep measures among caregivers is important because these populations are often at high risk for poor sleep and other comorbidities, which can have deleterious consequences on both the caregiver and care recipient. ${ }^{20-24}$

Caregivers report poorer sleep outcomes, greater anxiety, and greater depression when compared to noncaregivers, ${ }^{19,25-28}$ and caregiver focus groups report that poor sleep has had negative impacts on health. ${ }^{20,29}$ Caregivers of children with chronic health conditions show greater depressive symptoms compared to caregivers of children without chronic health conditions. ${ }^{26}$ In addition, a graded relationship between caregiving burden and depression was observed when comparing caregivers of children with both neurodevelopmental and behavioral disorders to caregivers of children with either one or none of these disorders. ${ }^{30}$ Therefore, we determined whether self-reported (subjective) sleep and wrist actigraphy (objective) sleep traits were each associated with depression and investigated the extent to which these associations differed among a sample of female caregivers of children with disabilities.

\section{Methods}

\section{Study participants}

The Chile Pediatric and Adult Sleep Study (CPASS) is a cross-sectional study conducted at the Centro de Rehabilitación Club de Leones Cruz del Sur in Punta Arenas, Chile that was designed to investigate the relationship between the sleep quality of children with disabilities and that of their primary caregivers with cardiometabolic and psychological health. This study was conducted among female primary caregivers of children with disabilities enrolled between September 2012 and July 2013 in two waves. The first wave (CPASS I) was conducted between September 2012 and December 2012 among caregivers of children aged 6-12 years receiving routine clinical care for disabilities at the center. The second wave (CPASS II) was conducted between April 2013 and July 2013 among caregivers of children with disabilities aged 10-21 years at the center. Both CPASS-I and CPASS-II study protocols have been described in further detail elsewhere. ${ }^{31,32}$ The primary caregiver was defined as an adult for whom the child's well-being was her principal responsibility. Primary caregivers included mothers, grandmothers, and relatives who were not diagnosed with developmental or intellectual disabilities. Research personnel invited 239 women, and from this group, 175 agreed to participate (73.2\%), each in the care of one child.

\section{Study procedures}

After obtaining written informed consent, a research psychologist administered structured questionnaires to women in order to collect information on sociodemographic and lifestyle factors and sleep characteristics. Following the structured interview, research staff instructed women to wear ActiSleep monitors (ActiLife; ActiGraph R\&D, Pensacola, FL, USA) on nondominant wrists for seven consecutive nights. Although monitors were waterproof, women were instructed to remove them before showering and swimming.

\section{Data collection instruments and covariates}

\section{Pittsburgh Sleep Quality Index (PSQI)}

Subjective sleep quality was assessed using PSQI, which measures sleep quality retrospectively over a 1-month period. The PSQI is a validated instrument for sleep research ${ }^{8,33}$ and consists of 24 questions that generate seven component scores, each with a scale of $0-3$; higher scores indicate poorer sleep outcomes. Component scores were then totaled for a global PSQI score ranging from 0 to 21, with higher scores indicating worse overall sleep quality. A global PSQI score $>5$ has been shown to yield a sensitivity of $89.6 \%$ and a specificity of $86.5 \%$ in distinguishing good (score $\leq 5$ ) and poor sleepers (score $>5$ ). ${ }^{8}$ Our analysis explored the following PSQI component scores: total time in bed (hours), sleep latency (minutes), sleep duration (hours), and sleep efficiency $(\%)$.

\section{Wrist actigraphy}

Objective sleep quality and disturbance were assessed with wrist actigraphy, an activity-based monitor to assess sleepwake patterns, which has been shown to be valid in healthy and sleep-disordered populations. ${ }^{34-37}$ Actigraphy data were collected using ActiSleep wrist-monitors that utilized Acti ${ }^{-}$ Life 6 data analysis software. Actigraphy-measured sleep data were collected in 1-minute epochs using the zero-crossing modes and the Cole-Kripke algorithm. ${ }^{9}$ Caregivers wore ActiSleep monitors for seven consecutive nights on nondominant wrists. Reported actigraphy-measured parameters include total time in bed (hours), sleep latency (minutes), 
sleep duration (hours), sleep efficiency (\%), wake after sleep onset (WASO; minutes); average awakening length (minutes), and number of awakenings. Actigraphy wrist-monitors were inspected and cleaned prior to distribution to ensure that devices were in working condition, and visual inspection of data was performed regularly.

\section{Patient Health Questionnaire}

Depression was assessed using the eight-item Patient Health Questionnaire (PHQ-8), which uses a self-administered module for unipolar depression that asks the participant "Over the last 2 weeks, how often have you been bothered by the following problems?" We did not include the ninth question from the nine-item Patient Health Questionnaire, which assesses for suicidal thoughts, because of the impracticality of timely clinical follow-up of positive responses. Also, in other studies, the modification of the nine-item Patient Health Questionnaire to the PHQ-8 depression questionnaire has been demonstrated to minimally influence overall scale performance, mean scores, or diagnostic cut points. ${ }^{38,39}$ The eight items of the PHQ-8 include feigned interest, hopelessness, trouble sleeping, lack of energy, changes in appetite, self-deprecation, trouble concentrating, and changes in physical behavior. The participant's endorsement of each item was ranked on a scale from 0 to 3 : not at all (0), several days (1), more than half of the days (2), and nearly every day (3). Response to each item was summed for a total PHQ-8 score ranging from 0 to 24 . Validated cutoffs were used to categorize patients into either depressed (PHQ-8 score $\geq 10$ ) or non-depressed (PHQ- 8 score $<10$ ) categories for comparison. ${ }^{38}$ Using the Diagnostic Statistical Manual, fourth edition, a score $\geq 10$ has been shown to be associated with $88 \%$ sensitivity and $88 \%$ specificity in diagnosing major depressive disorder ${ }^{38}$ and validated for use in Spanishspeaking populations..$^{40,41}$

\section{Covariates}

Structured interviewer-administered questionnaires collected data on caregivers' age, body mass index (BMI), ethnicity, marital status, current smoking status, alcohol consumption, employment status, and education level. BMI was calculated from the caregivers' weight measured to the nearest $0.1 \mathrm{~kg}$, and height was measured with a telescopic height instrument to the nearest $0.1 \mathrm{~cm}$. According to the International Classification of Diseases, tenth revision, ${ }^{42}$ children's disabilities were grouped as follows: 1) mental and behavioral disorders (eg, autism); 2) diseases of the musculoskeletal system and connective tissue, skin, and subcutaneous system (eg, scoliosis); 3) diseases of the nervous system (eg, cerebral palsy); and 4) congenital malformations and chromosomal abnormalities (eg, Down syndrome). Electronic medical records were reviewed to confirm children's diagnoses.

\section{Statistical analysis}

The Fisher's exact and chi-square tests were used to evaluate differences in sociodemographic and lifestyle characteristics by caregiver depression status (PHQ- 8 score of $\geq 10$ vs PHQ-8 score $<10$ ). Differences in sleep between depressed women and nondepressed women were analyzed for both subjective and objective sleep parameters using either Student's $t$-test or Kruskal-Wallis test. Among depressed and non-depressed groups, overlapping objective and subjective sleep parameters were compared using either paired $t$-tests or signed tests for matched pairs. Continuous nonparametric sleep variables were $\log$ transformed for regression analysis. Linear regression models were fit for each dependent sleep parameter. Depression and other covariates were independent variables. Multivariable models were adjusted for BMI (continuous), marital status (married or living with a partner vs divorced/ separated/widowed/never married), current smoking status (yes or no), education level (< high school, high school, or $>$ high school), and children's disability group (mental and behavioral disorders, diseases of musculoskeletal system and connective/skin tissue, diseases of the nervous system, or congenital malformations and chromosomal abnormalities). A sensitivity analysis excluding the "trouble sleeping" item from the PHQ-8 was performed for the association between subjective sleep and depression. Statistical significance levels were set at a $P$-value $<0.05$ for two-sided analysis, and where appropriate, SDs, regression coefficients, and standard errors (SEs) were reported. All statistical analyses were performed using SAS ${ }^{\circledR}$ Version 9.3 (SAS Institute Inc., Cary, NC, USA).

\section{Ethical consideration}

This study was approved by the institutional review boards of the Harvard T.H. Chan School of Public Health and the Centro de Rehabilitación Club de Leones Cruz del Sur in Punta Arenas, Chile. Written informed consent was obtained from all participants.

\section{Results}

Our sample consisted of 175 female primary caregivers with a mean age of 40.6 years $(\mathrm{SD}=8.7)$. Sociodemographic characteristics of study participants are summarized in Table 1. Using a PHQ-8 score $\geq 10,26.3 \%$ of participants presented 
Table I Sociodemographic characteristics of 175 female caregivers of children with disabilities, by depression status

\begin{tabular}{|c|c|c|c|c|}
\hline & $\begin{array}{l}\text { Total } \\
(n=\mid 75)\end{array}$ & $\begin{array}{l}\text { Depressed } \\
\text { women } \\
(n=46)\end{array}$ & $\begin{array}{l}\text { Nondepressed } \\
\text { women } \\
(n=129)\end{array}$ & $P$-value ${ }^{a}$ \\
\hline Age (years), mean (SD) & $40.6(8.7)$ & $40.6(7.9)$ & $40.6(8.9)$ & 0.989 \\
\hline Hispanic, n (\%) & $82(46.9)$ & $21(45.7)$ & $61(47.3)$ & 0.849 \\
\hline \multicolumn{5}{|l|}{ Marital status, n (\%) } \\
\hline Married or living with a partner & $116(66.3)$ & $23(50.0)$ & 93 (72.I) & \multirow[t]{2}{*}{0.007} \\
\hline Divorced/separated/widowed/never married & $59(33.7)$ & $23(50.0)$ & $36(27.9)$ & \\
\hline BMI $\left(\mathrm{kg} / \mathrm{m}^{2}\right)$, mean $(\mathrm{SD})$ & $29.6(5.6)$ & $31.0(6.3)$ & $29.0(5.3)$ & 0.037 \\
\hline Current smoker, n (\%) & $82(46.9)$ & $29(63.0)$ & $53(4 I . I)$ & 0.010 \\
\hline Alcohol consumption, $\mathrm{n}(\%)$ & $30(17.1)$ & $5(10.9)$ & $25(19.4)$ & 0.189 \\
\hline Unemployed/student, n (\%) & $79(45.1)$ & $22(47.8)$ & $57(44.2)$ & 0.670 \\
\hline \multicolumn{5}{|l|}{ Education level, $\mathrm{n}(\%)$} \\
\hline$<$ High school & $60(34.3)$ & $23(50.0)$ & $37(28.7)$ & \multirow[t]{3}{*}{0.013} \\
\hline High school & $59(33.7)$ & $15(32.6)$ & $44(34.1)$ & \\
\hline >High school & $56(32.0)$ & $8(17.4)$ & $48(37.2)$ & \\
\hline \multicolumn{5}{|l|}{ Child disability group, $\mathrm{n}(\%)$} \\
\hline Mental and behavioral disorders & $75(42.9)$ & $17(37.0)$ & $58(45.0)$ & \multirow[t]{4}{*}{0.713} \\
\hline Diseases of musculoskeletal system and connective/skin tissue & $32(18.3)$ & $8(17.4)$ & $24(18.6)$ & \\
\hline Diseases of the nervous system & $47(26.9)$ & $14(30.4)$ & $33(25.6)$ & \\
\hline Congenital malformations and chromosomal abnormalities & $21(12.0)$ & $7(15.2)$ & $14(10.9)$ & \\
\hline
\end{tabular}

Notes: Depression was defined using the PHQ-8 score $\geq 10$. a'Student's $t$-test was conducted for age and BMI; chi-square test was conducted for other sociodemographic characteristics (categorical variables). $P$-values less than 0.05 are shown in bold.

Abbreviations: BMI, body mass index; PHQ-8, eight-item Patient Health Questionnaire.

with depression. When compared with nondepressed women, depressed women had higher mean BMI $\left(31.0 \mathrm{~kg} / \mathrm{m}^{2} \mathrm{vs}\right.$ $\left.29.0 \mathrm{~kg} / \mathrm{m}^{2} ; P=0.037\right)$, were less likely to report being married or living with a partner $(50.0 \%$ vs $72.1 \% ; P=0.007)$, were more likely to report being a current smoker $(63.0 \%$ vs $41.1 \% ; P=0.010)$, and were less likely to report a completed education beyond high school $(17.4 \%$ vs $37.2 \% ; P=0.013)$. The majority of women cared for children with mental and behavioral disorders (42.9\%), followed by children with nervous tissue diseases (26.9\%), musculoskeletal and connective tissue diseases (18.3\%), and congenital and chromosomal abnormalities (12.0\%). However, the children's disability group did not statistically differ by caregivers' depression status ( $P=0.713$ ). Other characteristics, including age, ethnicity, alcohol consumption, and employment status, did not statistically differ by depression status.

Table 2 shows differences in subjective and objective sleep parameters comparing depressed and nondepressed women as well as univariate and multivariable regression coefficients for the association between sleep and depression. Compared with nondepressed women, depressed women self-reported shorter total time in bed ( 6.6 hours vs 7.3 hours; $P=0.014$ ), longer sleep latency (60.0 minutes vs 20.0 minutes; $P<0.001$ ), shorter sleep duration (5.8 hours vs 6.6 hours; $P=0.001)$, and poorer overall sleep quality using the median global PSQI score (11.0 vs $6.0 ; P<0.001)$. No statistically significant differences were observed using subjective sleep efficiency ( $88.2 \%$ vs $91.7 \% ; P=0.570)$. Similar to subjective sleep duration, objective sleep duration differed comparing depressed and nondepressed women (6.4 hours vs 6.9 hours; $P=0.005)$. Depressed women did not statistically differ from non-depressed women based on objective total time in bed (7.7 hours vs 8.1 hours; $P=0.076$ ), objective sleep latency (7.2 minutes vs 11.1 minutes; $P=0.453$ ), objective sleep efficiency ( $86.2 \%$ vs $87.2 \% ; P=0.191)$, objective WASO (54.6 minutes vs 50.9 minutes; $P=0.361$ ), objective number of awakenings ( 14.4 vs $13.6 ; P=0.565)$, and objective average awakening length (4.7 minutes vs 4.7 minutes; $P=0.921$ ).

Table 2 also shows differences between subjective and objective sleep parameters within depression status groups. Among the depressed group, the mean subjective total time in bed (6.6 hours) was lower than the mean objective total time in bed (7.7 hours) and the difference statistically significant ( -1.1 hours, 95\% Confidence Interval [CI]: -1.5 to $-0.7 ; P<0.001)$. Among the nondepressed, the mean subjective total time in bed ( 7.3 hours) was lower than the mean objective total time in bed ( 8.1 hours) and the difference statistically significant ( -0.8 hours, $95 \% \mathrm{CI}:-1.1$ to -0.5 ; $P<0.001)$. Among the depressed group, the mean subjective sleep duration (5.8 hours) was lower than the mean objective sleep duration (6.4 hours) and the difference statistically significant ( -0.6 hours, 95\% CI: -1.0 to $-0.2 ; P=0.005)$. Among the nondepressed, the mean subjective sleep duration (6.6 hours) was lower than the mean objective sleep duration 
Table 2 Differences in subjective and objective-measured sleep parameters between depressed and non-depressed women

\begin{tabular}{|c|c|c|c|c|c|c|c|}
\hline \multirow[t]{2}{*}{ Dependent variables } & \multirow[t]{2}{*}{$\begin{array}{l}\text { Depressed } \\
(n=46)\end{array}$} & \multirow[t]{2}{*}{$\begin{array}{l}\text { Nondepressed } \\
(n=129)\end{array}$} & \multirow[t]{2}{*}{$P$-value ${ }^{a}$} & \multicolumn{2}{|l|}{$\begin{array}{l}\text { Univariate } \\
\text { models }\end{array}$} & \multicolumn{2}{|c|}{$\begin{array}{l}\text { Multivariable } \\
\text { models }^{\mathrm{b}}\end{array}$} \\
\hline & & & & $\beta(\mathrm{SE})$ & $P$-value & $\beta(\mathrm{SE})$ & $P$-value \\
\hline \multicolumn{8}{|l|}{ Subjective: PSQI-reported sleep parameters } \\
\hline Total time in bed (hours), mean (SD) & $6.6(1.5)$ & $7.3(1.6)$ & 0.014 & $-0.67(0.27)$ & 0.014 & $-0.61(0.29)$ & 0.033 \\
\hline Sleep latency (minutes), median (interquartile) ${ }^{c}$ & $60.0(30.0,90.0)$ & $20.0(10.0,60.0)$ & $<0.001$ & $0.72(0.19)$ & $<0.00$ I & $0.58(0.20)$ & 0.003 \\
\hline Sleep duration (hours), mean (SD) & $5.8(1.3)$ & $6.6(1.4)$ & 0.001 & $-0.81(0.24)$ & 0.001 & $-0.7 \mid(0.25)$ & 0.006 \\
\hline Sleep efficiency (\%), median (interquartile) ${ }^{c}$ & $88.2(77.4,100.0)$ & $91.7(80.0,100.0)$ & 0.570 & $-0.02(0.03)$ & 0.540 & $-0.01(0.03)$ & 0.743 \\
\hline Global PSQI score, median (interquartile) & $11.0(9.0,13.0)$ & $6.0(4.0,9.0)$ & $<0.001$ & $0.56(0.08)$ & $<0.001$ & $0.53(0.08)$ & $<0.001$ \\
\hline \multicolumn{8}{|c|}{ Objective: actigraphy-measured sleep parameters ${ }^{d}$} \\
\hline Total time in bed (hours), mean (SD) & $7.7(1.3)$ & $8.1(1.3)$ & 0.076 & $-0.40(0.22)$ & 0.076 & $-0.32(0.23)$ & 0.174 \\
\hline Sleep latency (minutes), median (interquartile) ${ }^{c}$ & $7.2(2.9,17.1)$ & II.I $(4.7,18.9)$ & 0.453 & $-0.15(0.23)$ & 0.513 & $-0.19(0.23)$ & 0.408 \\
\hline Sleep duration (hours), mean (SD) & $6.4(0.9)$ & $6.9(1.0)$ & 0.005 & $-0.5 \mathrm{I}(0.18)$ & 0.005 & $-0.42(0.19)$ & 0.026 \\
\hline Sleep efficiency (\%), median (interquartile) ${ }^{c}$ & $86.2(80.0,88.9)$ & $87.2(81.6,90.0)$ & 0.191 & $-0.02(0.01)$ & 0.123 & $-0.02(0.01)$ & 0.210 \\
\hline WASO (minutes), median (interquartile) & $54.6(42.1,75.2)$ & $50.9(35.4,75.6)$ & 0.361 & $0.09(0.10)$ & 0.339 & $0.11(0.10)$ & 0.274 \\
\hline $\begin{array}{l}\text { Average awakening length (minutes), median } \\
\text { (interquartile) }^{c}\end{array}$ & $4.7(3.2,7.2)$ & $4.7(3.5,6.6)$ & 0.921 & $-0.002(0.09)$ & 0.985 & $-0.06(0.09)$ & 0.531 \\
\hline Number of awakenings, median (interquartile) ${ }^{c}$ & $14.4(11.6,18.4)$ & $13.6(10.4,17.7)$ & 0.565 & $0.03(0.08)$ & 0.701 & $0.08(0.08)$ & 0.366 \\
\hline
\end{tabular}

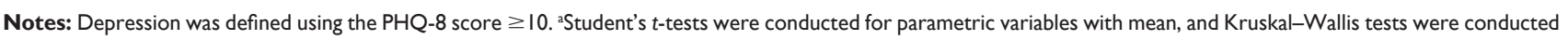
for nonparametric variables with median. 'Models were adjusted for women's body mass index (continuous), marital status, current smoking status, education level, and children's disability group. 'Log transformation was made for nonparametric variables in the linear regression models. ${ }^{\text {DFor }}$ actigraphy-measured sleep parameters, the number of depressed women was 44, while the number of nondepressed women was 127. P-values less than 0.05 are shown in bold.

Abbreviations: SE, standard error; PSQI, Pittsburgh Sleep Quality Index; WASO, wake after sleep onset; PHQ-8, eight-item Patient Health Questionnaire.

(6.9 hours); however, the difference was not statistically significant ( -0.3 hours, $95 \% \mathrm{CI}:-0.54$ to $0.01 ; P=0.059$ ). Among the depressed, the median subjective sleep latency (60.0 minutes) was higher than the median objective sleep latency (7.2 minutes) and difference statistically significant $(P<0.001)$. Among the nondepressed, the median subjective sleep latency (20.0 minutes) was higher than the median objective sleep latency (11.1 minutes) and the difference statistically significant $(P<0.001)$. Among the depressed group, the median subjective sleep efficiency $(88.2 \%)$ was higher than the median objective sleep efficiency (86.2\%); however, the difference was not statistically significant $(P=0.451)$. Among the nondepressed group, the median subjective sleep efficiency $(91.7 \%)$ was higher than the median objective sleep efficiency (87.2\%) and the difference was statistically significant $(P=0.019)$.

All multivariable models were adjusted for BMI (continuous), marital status, current smoking status, education level, and children's disability group. Subjective multivariable models show depression to be negatively associated with total time in bed $(\beta=-0.61, \mathrm{SE}=0.29 ; P=0.033)$ and sleep duration $(\beta=-0.71, \mathrm{SE}=0.25 ; P=0.006)$ and positively associated with subjective sleep latency $(\beta=0.58, \mathrm{SE}=0.20$; $P=0.003$ ) and subjective overall poor sleep quality using the global PSQI score $(\beta=0.53, \mathrm{SE}=0.08 ; P<0.001)$. Depression was also negatively associated with objective sleep duration $(\beta=-0.42, \mathrm{SE}=0.19 ; P=0.026)$. No statistically significant associations were found for subjective sleep efficiency $(\beta=-0.01, \mathrm{SE}=0.03 ; P=0.743)$, objective total time in bed ( $\beta=-0.32, \mathrm{SE}=0.23 ; P=0.174)$, objective sleep latency ( $\beta=-0.19, \mathrm{SE}=0.23 ; P=0.408)$, objective sleep efficiency $(\beta=-0.02, \mathrm{SE}=0.01 ; P=0.210)$, objective WASO $(\beta=0.11$, $\mathrm{SE}=0.10 ; P=0.274)$, objective average awakening length ( $\beta=-0.06, \mathrm{SE}=0.09 ; P=0.531$ ), and objective number of awakenings $(\beta=0.08, \mathrm{SE}=0.08 ; P=0.366)$. Table 3 shows the results from the sensitivity analyses that excluded the "trouble sleeping" item from the PHQ-8. Results from the sensitivity analyses did not substantially change the subjective associations previously reported in Table 2. Notably, subjective sleep latency was no longer statistically significant in multivariable models $(\beta=0.30, \mathrm{SE}=0.22 ; P=0.184)$. Changes in objective associations also did not substantially differ (data not shown).

\section{Discussion}

Our study found an association between some sleep traits and depression and a difference in the extent of the association when comparing subjective and objective sleep measures. Our study also observed an overall underestimation of total time in bed and sleep duration, although only the underestimation among the depressed group was statistically significant. We also report a robust negative association between depression and sleep duration using both subjective and objective sleep measures, and that the magnitude of association was strongest using subjective sleep measures. In addition, we found that the prevalence of depression among caregivers 
Table 3 Differences in subjective sleep parameters between depressed and nondepressed women (PHQ-8 excluded item 3: trouble sleeping)

\begin{tabular}{|c|c|c|c|c|c|c|c|}
\hline \multirow[t]{2}{*}{ Dependent variables } & \multirow[t]{2}{*}{$\begin{array}{l}\text { Depressed } \\
(n=32)\end{array}$} & \multirow[t]{2}{*}{$\begin{array}{l}\text { Nondepressed } \\
(n=143)\end{array}$} & \multirow[t]{2}{*}{$P$-value ${ }^{a}$} & \multicolumn{2}{|l|}{$\begin{array}{l}\text { Univariate } \\
\text { models }\end{array}$} & \multicolumn{2}{|c|}{$\begin{array}{l}\text { Multivariable } \\
\text { models }^{\mathbf{b}}\end{array}$} \\
\hline & & & & $\beta$ (SE) & $P$-value & $\beta(\mathrm{SE})$ & $P$-value \\
\hline \multicolumn{8}{|l|}{ Subjective: PSQI-reported sleep parameters } \\
\hline Total time in bed (hours), mean (SD) & $6.3(1.4)$ & $7.3(1.6)$ & 0.001 & $-1.00(0.30)$ & 0.001 & $-0.98(0.3 \mathrm{I})$ & 0.002 \\
\hline Sleep latency (minutes), median (interquartile) ${ }^{c}$ & $52.5(20.0,75.0)$ & $30.0(10.0,60.0)$ & 0.021 & $0.45(0.22)$ & 0.041 & $0.30(0.22)$ & 0.184 \\
\hline Sleep duration (hours), mean (SD) & $5.5(1.2)$ & $6.6(1.4)$ & $<\mathbf{0 . 0 0 1}$ & $-1.12(0.27)$ & $<\mathbf{0 . 0 0 1}$ & $-1.02(0.27)$ & $<\mathbf{0 . 0 0 1}$ \\
\hline Sleep efficiency (\%), median (interquartile) ${ }^{c}$ & $88.9(78.7,100.0)$ & $91.7(77.8,100.0)$ & 0.907 & $-0.02(0.03)$ & 0.497 & $-0.01(0.03)$ & 0.692 \\
\hline Global PSQI score, median (interquartile) ${ }^{c}$ & II.5 $(9.0,14.0)$ & $7.0(5.0,9.0)$ & $<0.001$ & $0.52(0.09)$ & $<0.001$ & $0.47(0.09)$ & $<0.001$ \\
\hline
\end{tabular}

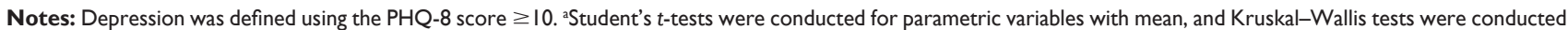
for nonparametric variables with median. 'Models were adjusted for women's body mass index (continuous), marital status, current smoking status, education level, and children's disability group. 'Log transformation was made for nonparametric variables in the linear regression models. $P$-values less than 0.05 are shown in bold.

Abbreviations: PHQ-8, eight-item Patient Health Questionnaire; SE, standard error; PSQI, Pittsburgh Sleep Quality Index.

in our study $(26.3 \%)$ was within the range of depression estimates reported in other studies of caregivers for children with disabilities $(15 \%-32 \%))^{30,43}$

Our finding of an association between some sleep traits and depression corroborates with the literature relating to this topic. ${ }^{1,3-7}$ Our finding of differences comparing subjective and objective sleep measures is also supported by much of the literature, ${ }^{10-19}$ despite limited findings to the contrary. ${ }^{44}$ Among studies that have looked at such differences among the depressed patients, they have reported that depressed patients are more likely to poorly recall aspects of sleep compared to the nondepressed patients. ${ }^{12-14}$ However, the direction of the inconsistency is mixed. For example, although we observed that depressed women significantly underreported sleep duration while nondepressed women did not, others have reported that depressed individuals may in fact be more likely to over report sleep duration. ${ }^{12}$ Finally, our finding of differences in the association between sleep and depression comparing subjective and objective sleep measures has also been previously reported. For example, in a recent study of pregnant women with and without a confirmed mental disorder, daily reported (subjective) sleep variables showed significant associations with patient status in multivariable models, while wrist actigraphy (objective) sleep did not. ${ }^{16}$

Results from a recent meta-analysis reported that when compared to normal sleep duration, short sleep duration is significantly associated with depression in adults (relative risk $=1.31,95 \%$ CI: 1.04 to 1.64$).{ }^{4}$ In our study, a robust negative association between depression and sleep duration was found using both subjective and objective sleep measures. Similar associations between mental health outcomes and sleep duration have been observed in other studies of caregivers. ${ }^{19,25}$ For example, in a sample of male and female caregivers, sleep duration was significantly associated with higher levels of depression using the Hospital Anxiety and Depression Scale. ${ }^{25}$ It is important to note that the association between sleep and depression is multifaceted and is impacted not only by changes in sleep features, such as shortened sleep duration, but also by changes in social and environmental factors. ${ }^{45,46}$ Interestingly, in a study among young adult women, perceived stress was associated with poorer subjective sleep quality but not with actigraphic (objective) sleep measures. ${ }^{47}$

Although perceived (subjective) and actual (objective) sleep measures share commonalities, it is not surprising that the two differ. Buysse et $\mathrm{a}^{48}$ and Vitiello et al ${ }^{49}$ have previously demonstrated that individuals adapt perception of "acceptable" sleep. For example, in a study of healthy older individuals, although participants reported no perceptions of poor sleep using subjective sleep measures, objective sleep measures showed significant sleep disturbances. ${ }^{49}$ In our case, the opposite may be occurring. Depressed individuals may have had altered perceptions of acceptable sleep in that they perceived and self-reported sleep disturbances, despite few observed differences from nondepressed individuals using objective sleep measures. It may also be the case that perception of sleep among individuals with a comorbid mood disorder is a function of cognition, severity of depression, and actual sleep, rather than actual sleep alone, as suggested in previous studies. ${ }^{13,14}$ Furthermore, shorter sleep duration interferes with memory consolidation, ${ }^{50}$ which may influence perception of sleep. ${ }^{51}$ Perceptions of poor sleep may then go on to influence sleep-disruptive compensatory behaviors, such as increased anxiety during times of rest, ${ }^{52}$ thereby perpetuating poor sleep among individuals who perceive that they sleep poorly.

Our study had several strengths including the use of validated sleep and depression instruments and analytical handling of potential confounders. Our study addressed 
confounding in two ways. First, we excluded women who were diagnosed with developmental or intellectual disabilities. This exclusion criterion reduced the potential confounding influence that caregivers' disability status might have had on both sleep and depression. Second, we adjusted for covariates associated with sleep and depression in our study population in multivariable models. However, we could not discount the possibility of residual confounding. Additionally, a sensitivity analysis showed that the influence of the PHQ-8 sleep criteria "trouble sleeping" did not substantially influence the observed associations between subjective sleep and depression. Despite these strengths, our study had some limitations. Our relatively small sample size might have affected our power to detect an association between sleep and depression in some instances. Additionally, our study was cross-sectional and thus was unable to determine the temporal association between sleep and depression. We could not distinguish whether perception of acceptable sleep was influenced by depression or whether depression was influenced by perception of acceptable sleep. We were also limited in our ability to report on other comorbid features associated with caregiving, including anxiety and perceived stress. Furthermore, the generalizability of our findings may also be limited to our specific study population and setting.

\section{Conclusion}

The health of caregivers is a twofold concern, in our case affecting both caregivers and children with disabilities. Rehabilitation providers for children with disabilities are well positioned to monitor the sleep and mental health of caregivers and provide the necessary resources, referrals, and interventions. Our study shows that the association between sleep and depression differs comparing subjective and objective methods of assessment and that short sleep duration is associated with depression using both subjective and objective sleep measures. Therefore, sleep intervention strategies for caregivers may benefit from a focus on sleep duration, and research strategies allowing for the integration of both perceived and objective measures of sleep traits are encouraged.

\section{Acknowledgments}

The National Institute of Health Training Grant in Psychiatric Epidemiology (T32-MH-017119) supported Olivia R Orta. An award from the National Institutes of Health also supported this research for minority health and health disparities (T37-MD-000149). The National Institutes of Health had no further role in study design; in the collection, analysis, and interpretation of data; in the writing of the report; and in the decision to submit the article for publication.

\section{Disclosure}

The authors, and the institutions with which they are affiliated, have no direct or indirect financial interest in the subject matter of this manuscript. The authors report no other conflicts of interest in this work.

\section{References}

1. Stranges S, Tigbe W, Gomez-Olive FX, Thorogood M, Kandala NB. Sleep problems: an emerging global epidemic? Findings from the INDEPTH WHO-SAGE study among more than 40,000 older adults from 8 countries across Africa and Asia. Sleep. 2012;35(8): 1173-1181.

2. Soldatos CR, Allaert FA, Ohta T, Dikeos DG. How do individuals sleep around the world? Results from a single-day survey in ten countries. Sleep Med. 2005;6(1):5-13.

3. Montero RF, Martinez PL, Gomez RR, Baltra RA, Castillo GR. Sleep disorders in the adult population of Santiago of Chile and its association with common psychiatric disorders. Actas Esp Psiquiatr. 2010;38(6):358-364.

4. Zhai L, Zhang H, Zhang D. Sleep duration and depression among adults: a meta-analysis of prospective studies. Depress Anxiety. 2015;32(9):664-670.

5. Maglione JE, Ancoli-Israel S, Peters KW, et al; Study of Osteoporotic Fractures Research Group. Subjective and objective sleep disturbance and longitudinal risk of depression in a cohort of older women. Sleep. 2014;37(7):1179-1187.

6. Tsuno N, Besset A, Ritchie K. Sleep and depression. J Clin Psychiatry. 2005;66(10):1254-1269.

7. Lemma S, Gelaye B, Berhane Y, Worku A, Williams MA. Sleep quality and its psychological correlates among university students in Ethiopia: a cross-sectional study. BMC Psychiatry. 2012;12:237.

8. Buysse DJ, Reynolds CF 3rd, Monk TH, Berman SR, Kupfer DJ. The Pittsburgh Sleep Quality Index: a new instrument for psychiatric practice and research. Psychiatry Res. 1989;28(2):193-213.

9. Cole RJ, Kripke DF, Gruen W, Mullaney DJ, Gillin JC. Automatic sleep/ wake identification from wrist activity. Sleep. 1992;15(5):461-469.

10. Baker FC, Maloney S, Driver HS. A comparison of subjective estimates of sleep with objective polysomnographic data in healthy men and women. J Psychosom Res. 1999;47(4):335-341.

11. Lauderdale DS, Knutson KL, Yan LL, Liu K, Rathouz PJ. Self-reported and measured sleep duration: how similar are they? Epidemiology. 2008;19(6):838-845.

12. Rotenberg VS, Indursky P, Kayumov L, Sirota P, Melamed Y. The relationship between subjective sleep estimation and objective sleep variables in depressed patients. Int J Psychophysiol. 2000;37(3):291-297.

13. Argyropoulos SV, Hicks JA, Nash JR, et al. Correlation of subjective and objective sleep measurements at different stages of the treatment of depression. Psychiatry Res. 2003;120(2):179-190.

14. Tsuchiyama K, Nagayama H, Kudo K, Kojima K, Yamada K. Discrepancy between subjective and objective sleep in patients with depression. Psychiatry Clin Neurosci. 2003;57(3):259-264.

15. Herring SJ, Foster GD, Pien GW, et al. Do pregnant women accurately report sleep time? A comparison between self-reported and objective measures of sleep duration in pregnancy among a sample of urban mothers. Sleep Breath. 2013;17(4):1323-1327.

16. Van Ravesteyn LM, Tulen JH, Kamperman AM, et al. Perceived sleep quality is worse than objective parameters of sleep in pregnant women with a mental disorder. J Clin Sleep Med. 2014;10(10):1137-1141. 
17. Baker FC, Sassoon SA, Kahan T, et al. Perceived poor sleep quality in the absence of polysomnographic sleep disturbance in women with severe premenstrual syndrome. J Sleep Res. 2012;21(5):535-545.

18. Van Den Berg JF, Van Rooij FJ, Vos H, et al. Disagreement between subjective and actigraphic measures of sleep duration in a populationbased study of elderly persons. J Sleep Res. 2008;17(3):295-302.

19. Castro CM, Lee KA, Bliwise DL, Urizar GG, Woodward SH, King AC. Sleep patterns and sleep-related factors between caregiving and non-caregiving women. Behav Sleep Med. 2009;7(3):164-179.

20. Murphy NA, Christian B, Caplin DA, Young PC. The health of caregivers for children with disabilities: caregiver perspectives. Child Care Health Dev. 2007;33(2):180-187.

21. Schulz R, Beach SR. Caregiving as a risk factor for mortality: the caregiver health effects study. JAMA. 1999;282(23):2215-2219.

22. Ejem DB, Drentea P, Clay OJ. The effects of caregiver emotional stress on the depressive symptomatology of the care recipient. Aging Ment Health. 2015;19(1):55-62.

23. Lokk J. Caregiver strain in Parkinson's disease and the impact of disease duration. Eur J Phys Rehabil Med. 2008;44(1):39-45.

24. Khan F, Pallant J, Brand C. Caregiver strain and factors associated with caregiver self-efficacy and quality of life in a community cohort with multiple sclerosis. Disabil Rehabil. 2007;29(16):1241-1250.

25. Argyriou AA, Karanasios P, Assimakopoulos K, et al. Assessing the quality of sleep in Greek primary caregivers of patients with secondary progressive multiple sclerosis: a cross-sectional study. J Pain Symptom Manage. 2011;42(4):541-547.

26. Brehaut JC, Kohen DE, Garner RE, et al. Health among caregivers of children with health problems: findings from a Canadian populationbased study. Am J Public Health. 2009;99(7):1254-1262.

27. Happe S, Berger K; FAQT Study Investigators. The association between caregiver burden and sleep disturbances in partners of patients with Parkinson's disease. Age Ageing. 2002;31(5):349-354.

28. Cadman D, Rosenbaum P, Boyle M, Offord DR. Children with chronic illness: family and parent demographic characteristics and psychosocial adjustment. Pediatrics. 1991;87(6):884-889.

29. Carter PA. Caregivers' descriptions of sleep changes and depressive symptoms. Oncol Nurs Forum. 2002;29(9):1277-1283.

30. Lach LM, Kohen DE, Garner RE, et al. The health and psychosocial functioning of caregivers of children with neurodevelopmental disorders. Disabil Rehabil. 2009;31(8):607-618.

31. Chen X, Velez JC, Barbosa C, et al. Smoking and perceived stress in relation to short salivary telomere length among caregivers of children with disabilities. Stress. 2015;18(1):20-28.

32. Chen X, Gelaye B, Velez JC, et al. Caregivers' hair cortisol: a possible biomarker of chronic stress is associated with obesity measures among children with disabilities. BMC Pediatr. 2015;15:9.

33. Gelaye B, Lohsoonthorn V, Lertmeharit S, et al. Construct validity and factor structure of the Pittsburgh Sleep Quality Index and epworth sleepiness scale in a multi-national study of African, South East Asian and South American college students. PLoS One. 2014;9(12):e116383.

34. Kushida CA, Chang A, Gadkary C, Guilleminault C, Carrillo O, Dement WC. Comparison of actigraphic, polysomnographic, and subjective assessment of sleep parameters in sleep-disordered patients. Sleep Med. 2001;2(5):389-396.
35. Sadeh A, Hauri PJ, Kripke DF, Lavie P. The role of actigraphy in the evaluation of sleep disorders. Sleep. 1995;18(4):288-302.

36. Sadeh A. The role and validity of actigraphy in sleep medicine: an update. Sleep Med Rev. 2011;15(4):259-267.

37. Marino M, Li Y, Rueschman MN, et al. Measuring sleep: accuracy, sensitivity, and specificity of wrist actigraphy compared to polysomnography. Sleep. 2013;36(11):1747-1755.

38. Kroenke K, Spitzer RL, Williams JB. The PHQ-9: validity of a brief depression severity measure. J Gen Intern Med. 2001;16(9):606-613.

39. Kroenke K, Spitzer RL, Williams JB, Lowe B. The Patient Health Questionnaire Somatic, Anxiety, and Depressive Symptom Scales: a systematic review. Gen Hosp Psychiatry. 2010;32(4):345-359.

40. Zhong Q, Gelaye B, Fann JR, Sanchez SE, Williams MA. Cross-cultural validity of the Spanish version of PHQ-9 among pregnant Peruvian women: a Rasch item response theory analysis. J Affect Disord. 2014;158:148-153.

41. Huang FY, Chung H, Kroenke K, Delucchi KL, Spitzer RL. Using the Patient Health Questionnaire-9 to measure depression among racially and ethnically diverse primary care patients. J Gen Intern Med. 2006;21(6):547-552.

42. Lancaster CA, Gold KJ, Flynn HA, Yoo H, Marcus SM, Davis MM. Risk factors for depressive symptoms during pregnancy: a systematic review. Am J Obstet Gynecol. 2010;202(1):5-14.

43. Brown ES, Gan V, Jeffress J, et al. Psychiatric symptomatology and disorders in caregivers of children with asthma. Pediatrics. 2006;118(6):e1715-e1720.

44. Armitage R, Trivedi M, Hoffmann R, Rush AJ. Relationship between objective and subjective sleep measures in depressed patients and healthy controls. Depress Anxiety. 1997;5(2):97-102.

45. Rosenthal NE, Sack DA, Gillin JC, et al. Seasonal affective disorder. A description of the syndrome and preliminary findings with light therapy. Arch Gen Psychiatry. 1984;41(1):72-80.

46. Billings AG, Cronkite RC, Moos RH. Social-environmental factors in unipolar depression: comparisons of depressed patients and nondepressed controls. J Abnorm Psychol. 1983;92(2):119-133.

47. Tworoger SS, Davis S, Vitiello MV, Lentz MJ, McTiernan A. Factors associated with objective (actigraphic) and subjective sleep quality in young adult women. J Psychosom Res. 2005;59(1):11-19.

48. Buysse DJ, Reynolds CF 3rd, Monk TH, Hoch CC, Yeager AL, Kupfer DJ. Quantification of subjective sleep quality in healthy elderly men and women using the Pittsburgh Sleep Quality Index (PSQI). Sleep. 1991;14(4):331-338.

49. Vitiello MV, Larsen LH, Moe KE. Age-related sleep change: gender and estrogen effects on the subjective-objective sleep quality relationships of healthy, noncomplaining older men and women. J Psychosom Res. 2004;56(5):503-510.

50. Buzsaki G. Memory consolidation during sleep: a neurophysiological perspective. J Sleep Res. 1998;7(suppl 1):17-23.

51. Akerstedt T, Hume K, Minors D, Waterhouse J. The meaning of good sleep: a longitudinal study of polysomnography and subjective sleep quality. J Sleep Res. 1994;3(3):152-158.

52. Carney CE, Edinger JD, Manber R, Garson C, Segal ZV. Beliefs about sleep in disorders characterized by sleep and mood disturbance. J Psychosom Res. 2007;62(2):179-188.
Nature and Science of Sleep

\section{Publish your work in this journal}

Nature and Science of Sleep is an international, peer-reviewed, open access journal covering all aspects of sleep science and sleep medicine, including the neurophysiology and functions of sleep, the genetics of sleep, sleep and society, biological rhythms, dreaming, sleep disorders and therapy, and strategies to optimize healthy sleep. The journal welcomes
Dovepress

original research, clinical \& epidemiological studies, reviews \& evaluations, case reports and extended reports. The manuscript management system is completely online and includes a very quick and fair peerreview system, which is all easy to use. Visit http://www.dovepress.com/ testimonials.php to read real quotes from published authors. 